\title{
Potential use of an anticancer drug gefinitib, an EGFR inhibitor, on allergic airway inflammation
}

\author{
Gyu Young Hur ${ }^{1 *}$, Sung Yong Lee ${ }^{1}$, \\ Seung Hyeun Lee ${ }^{1}$, Se Joong Kim ${ }^{1}$, \\ Kyoung Ju Lee ${ }^{1}$, Jin Yong Jung ${ }^{1}$, \\ Eun Joo Lee', Eun Hae Kang ${ }^{1}$, \\ Ki Hwan Jung', Sang Yeub Lee ${ }^{1}$, \\ Je Hyeong Kim ${ }^{1}$, Chol Shin ${ }^{1}$, \\ Jae Jeong Shim ${ }^{1,2}$, Kwang Ho In $^{1}$, \\ Kyung Ho Kang ${ }^{1}$ and Se Hwa Yoo \\ ${ }^{1}$ Department of Internal Medicine \\ College of Medicine, Korea University \\ Seoul 152-703, Korea \\ ${ }^{2}$ Corresponding author: Tel, 82-2-2626-3029; \\ Fax, 82-2-830-2208; E-mail, jaejshim@kumc.or.kr \\ *Present address: Allergy and Rheumatology \\ Ajou University School of Medicine \\ Suwon 443-721, Korea
}

Accepted 9 April 2007

Abbreviations: AHR, airway hyperresponsiveness; BALF, bronchoalveolar lavage fluid; OVA, ovalbumin; PI3K, phosphoinositol 3'-kinase

\begin{abstract}
The EGFR plays an essential role in goblet cell hyperplasia and mucus hypersecretion. EGFR has an intrinsic tyrosine kinase activity that, when activated, induces the production of MUC5AC through the signaling kinase cascade in the airway epithelium. We have investigated the effects of an EGFR tyrosine kinase inhibitor, gefitinib, on ovalbumin (OVA)-induced, allergic inflammation in airway epithelia of mice. OVA-sensitized mice were pretreated with gefitinib at two different doses (12.5 and $50 \mathrm{mg} / \mathrm{kg}$ ) and then challenged with OVA. The OVA challenge increased the total cell count and eosinophil count in bronchoalveolar lavage fluid (BALF), as well as the concentrations of T-helper2 (Th2) cytokines, such as IL-4 and IL-13, overall eosinophil recruitment in the lung tissue and airway hyperresponsiveness (AHR). Pretreatment with gefitinib reduced the inflammatory cell counts and released cytokine concentrations (IL-4 and IL-13) in BALF, as well as eosinophil recruitment in the lungs and AHR, in a dose-dependent manner. This was
\end{abstract}

associated with decreased EGFR and Akt phosphorylation. We showed that gefitnib inhibits EGFR and phosphoinositol 3'-kinase (PI3K)/Akt activation which were activated in OVA sensitized mice. These findings suggest that inhibitors of the EGFR cascade may have a role in the treatment of asthma.

Keywords: asthma; gefitinib; mucins; 1-phosphatidylinositol 3-kinase; proto-oncogene proteins c-akt; receptor, epidermal growth factor

\section{Introduction}

Bronchial asthma is a chronic inflammatory disease of airways characterized by eosinophilic infiltration and airway hyperrespensiveness (AHR). Pathological features of asthma include pulmonary infiltration by eosinophils, lymphocytes, and mast cells, and structural changes of the airways, including bronchial wall thickening, subepithelial fibrosis, and goblet cell and airway smooth muscle hyperplasia (Cohn et al., 2004). T-helper 2 (Th2) cells have been proposed to play an essential role in allergic airway inflammation, and there are many studies that examine the functional effects of Th2 cells in asthmatics (Robinson et al., 1992). To date, accumulating data from mice and humans have identified Th2 cytokines, such as IL-4, IL-5, and IL-13, as major contributors to allergy and asthma (Ngoc et al., 2005).

Protein tyrosine kinases are essential for the activation and proliferation of inflammatory cells and airway-resident cells. EGFR is a member of the receptor tyrosine kinase family. On ligand binding, EGFR homodimerise or heterodimerise, thereby inducing intrinsic kinase activities that initiate intracellular signal transduction cascades including the Ras/Raf/MAPK pathway, the phosphatidylinositol 3-kinase (PI3K)/Akt pathway, and the STAT pathway (Bogdan and Klambt, 2001). The degree of EGFR expression reflects the epithelial damage and activation, and increases in proportion to asthma severity (Amishima et al., 1998; Puddicombe et al., 2000; Burgel and Nadel, 2004; Wong, 2005). Activated EGFR also has an essential role in mucin production in airway epithelium (Takeyama et al., 1999, 2001; Nadel, 2001; Nadel and Burgel, 2001). It induces airway goblet cell hyperplasia and enhances the expression of mucin genes, such as MUC5AC. When EGFR is activated, its ligands induce MUC5AC pro- 
duction through the signaling tyrosine kinase cascade in the airway (Deshmukh et al., 2005). Therefore, inhibitors of tyrosine kinase have been widely studied as a novel therapeutic strategy for the treatment of asthma (Vargaftig and Singer, 2003). Recent studies suggest that PI3K may contribute to the pathogenesis of asthma by effecting the recruitment, activation, and apoptosis of inflammatory cells (Pinho et al., 2005). Gefitinib, an EGFR tyrosine kinase inhibitor, is an active agent in non- small cell lung cancer (Gandara et al., 2004). Gefitinib blocks signal kinase transduction through EGFR and inhibits the proliferation and survival of cancer cells. As mentioned above, EGFR regulates mucin accumulation in the goblet cells of airway epithelium. There are some reports of an inhibitory effect of gefitinib on MUC5AC synthesis in mucin-secreting, non-small cell lung cancer, which was determined by blocking the EGFR signaling cascade (Kitazaki et al., 2005a, b).

Here, we investigated the inhibitory effects of the EGFR tyrosine kinase inhibitor gefitinib on OVAinduced allergic inflammation in mice in vivo. We hypothesized that the EGFR tyrosine kinase inhibitor would inhibit allergic inflammation by blocking the tyrosine kinase signaling cascade.

\section{Materials and Methods}

All experimental procedures were conducted in accordance with the standard guidelines for animal experiments of College of Medicine, Korea University.

\section{Animals, immunization, and materials}

Male BALB/c mice (Orient Ltd., Korea), weighing about $15 \mathrm{~g}$, were housed in a temperature- and humidity-controlled room; standard laboratory food and water were provided freely. The animals were assigned at random to a normal control group or to ovalbumin (OVA; Grade V ovalbumin, Sigma, St. Louis, MO)-induced control or treatment groups. Five animals were studied in each group. The mice in the OVA groups were immunized intraperitoneally with 10 $\mu \mathrm{g}$ of OVA and $4 \mathrm{mg}$ of aluminum hydroxide (Sigma) in $0.1 \mathrm{ml}$ of normal saline on days 0 and 7 . On days 14 and 15, the mice were anesthetized with methoxyflurane (Mallinckrodt Veterinary, Mundelein, IL), administered by inhalation, and $10 \mu \mathrm{g}$ of OVA in $50 \mu \mathrm{l}$ of PBS were administrated intranasally.

To evaluate the effects of the EGFR tyrosine kinase inhibitor, gefitinib on allergic inflammation in the OVAsensitized mouse airway, the mice were treated with purified gefitinib (12.5 or $50 \mathrm{mg} / \mathrm{kg}$, AstraZeneca, UK) administered by oral gavage for the duration of the experiment, beginning 1 day before the OVA challenge and continuing daily until the animals were sacrificed. Bronchoalveolar lavage $(B A L)$ was performed in five mice from each group $72 \mathrm{~h}$ after the last OVA challenge. For histologic evaluation, five additional mice from each group were sacrificed $72 \mathrm{~h}$ after the last challenge.

\section{BAL cell and cytokine analysis}

The number of eosinophil and neutrophil in the BAL was quantitated at $24 \mathrm{~h}$ intervals after the last challenge. These cell's counts progressively increased in the lung lavage from pilot study. Eosinophil and neutrophil count started within $24 \mathrm{~h}$ after the last intranasal challenge and reached maximum levels at $72 \mathrm{~h}$ (data not shown). After $72 \mathrm{~h}$, the number of eosinophil and neutrophil dropped but were still elevated compared with the $24 \mathrm{~h}$ time point. Based on this observation, mice were sacrificed $72 \mathrm{~h}$ after the last intranasal challenge, and the collected BALF was used for cytospin preparations. The slides were fixed and stained with Diff-Quick (Baxter Healthcare, McGaw Park, IL), and differential cell counts were obtained using light microscopic evaluation of 300 cells per slide. Total BAL cell counts were performed with a hemocytometer. After the removal of cells from the BALF by centrifugation, 100- $\mu$ laliquots were analyzed by ELISA for the presence of IL-4 and IL-13, using commercially available kits and following the manufacturer's instructions (Biosource, Camarillo, CA) (Kim et al., 2006).

\section{Tissue preparation}

Animals were euthanized with ketamine $(5 \mathrm{mg} / \mathrm{kg}$, intraperitoneal) 3 days after the last OVA challenge. Protein extracts isolated from the left lung of each mouse were used for Western blotting. The systemic circulation was perfused with $1 \%$ paraformaldehyde in diethylpyrocarbonate (Sigma)-treated PBS via the left ventricle. For paraffin sections, tissues were placed in $4 \%$ paraformaldehyde overnight, dehydrated with ethanol, and embedded in paraffin. The embedded tissues were cut as $4-\mu m$-thick cross sections and placed on glass slides.

\section{Quantification of goblet cell metaplasia}

The areas positive for Alcian blue $(A B)$ and periodic acid-Schiff (PAS) staining and the total epithelial area were measured, and the AB-PAS areas were expressed as a percentage of the total epithelial area. The stained slides were examined under a light microscope (Olympus BX51, Tokyo, Japan) connected to a video camera (Olympus DP 50, Tokyo, Japan), and the images were captured with a Viewfinder program (Viewfinder Lite v. 1.0; Pixera Co., Los. Gatos, CA). Images of the airway epithelium were recorded from 
six consecutive high-power fields at $\times 400$. The analysis was performed with the SigmaScan Pro program (SPSS Inc., Chicago, IL).

\section{Immunohistochemistry of EGFR}

The expression of activated EGFR was examined using immunohistochemical staining with an antibody specific for phospho-EGFR (P-EGFR, Cell Signaling Technology Inc., Beverly, MA). Images were viewed with an Olympus BX60 microscope and captured with a Viewfinder program. For each section, the extent of P-EGFR staining was graded on a scale of 0 to $(2+)$, with 0 representing no detectable staining, (1+) positive staining in $\leq 50 \%$ of total bronchial epithelial area, and $(2+)$ representing positive staining in > $50 \%$ of total bronchial epithelial area.

\section{Immunoblotting for activated EGFR}

Left lung tissues for Western blotting were scraped and lysed with whole lysis buffer (Mammalian protein extract, M-PER; Pierce, Rockford, IL), and a protease inhibitor cocktail (Pierce) was added. Total proteins were separated by SDS-PAGE in $8 \%$ Tris-glycine gels and transferred electrophoretically to polyvinylidene fluoride membranes. The membranes were incubated in $5 \%$ fat-free milk in TBS containing $0.05 \%$ Tween 20 for $1 \mathrm{~h}$ and then incubated with P-EGFR antibody (1:1,000, Cell Signaling Technology Inc.), anti-P-44/42 MAPK (1:1,000, Cell Signaling Technology Inc.), anti-P-Akt antibody $(1: 1,000$, Calbiochem) and $\beta$-actin $\left(1: 20,000\right.$, Sigma) at $4^{\circ} \mathrm{C}$ overnight. After washing, the membranes were incubated with anti-rabbit IgG HRP-linked secondary antibody $(1: 2,000$, Vector Laboratories, Inc.). Bound antibody was visualized using SuperSignal West Pico chemiluminescent substrate (Pierce).

\section{Measurement of airway hyperresponsiveness (AHR)}

Enhanced pauses (Penh) of the airway were assessed for indices of AHR in unrestrained conscious mice at $24 \mathrm{~h}$ after the final OVA challenge by using a single-chamber whole-body plethysmograph (Allmedicus, Anyang, Korea). In the plethysmograph, mice were exposed for $3 \mathrm{~min}$ to nebulized PBS and subsequently to increasing concentrations of nebulized methacholine (Sigma) in PBS, using an aerosonic ultrasonic nebulizer (DeVilbiss, Somerset, PA). After each nebulization, recordings were taken for $3 \mathrm{~min}$. The Penh values measured during each 3-min sequence were averaged and are expressed for each methacholine concentration $(3-50 \mathrm{mg} / \mathrm{ml})$ as a percentage of the baseline Penh value following PBS exposure.

\section{Statistics}

All data were expressed as the mean \pm SEM. Oneway ANOVA was used to determine statistically significant differences between groups. Scheffé's F-test was used to correct for multiple comparisons when statistical significances were identified by ANOVA. Differences were considered significant at the level of $P<0.05$.

\section{Results}

\section{Cell and cytokine levels in BALF of OVA-induced mice}

OVA exposure increased the total cell count and the eosinophil count in the BALF compared with the counts in the BALF of the normal control group. The BALF of control mice contained few inflammatory cells, and OVA stimulation of the airways caused eosinophil recruitment. Pretreatment with gefitinib inhibited the recruitment of eosinophils in the BALF in a dosedependent manner (Figure 1). The concentrations of IL-4 and IL-13 were significantly increased in the groups exposed to OVA. Both of these cytokines are consistent with a Th2 cytokine profile. In the gefitinibtreated group, the levels of both cytokines were decreased in a dose-dependent manner (Figure 2).

\section{Effects of gefitinib on goblet cell production in mouse airway}

In control animals, the airway epithelium showed sparse positive staining with AB/PAS. Exposure to

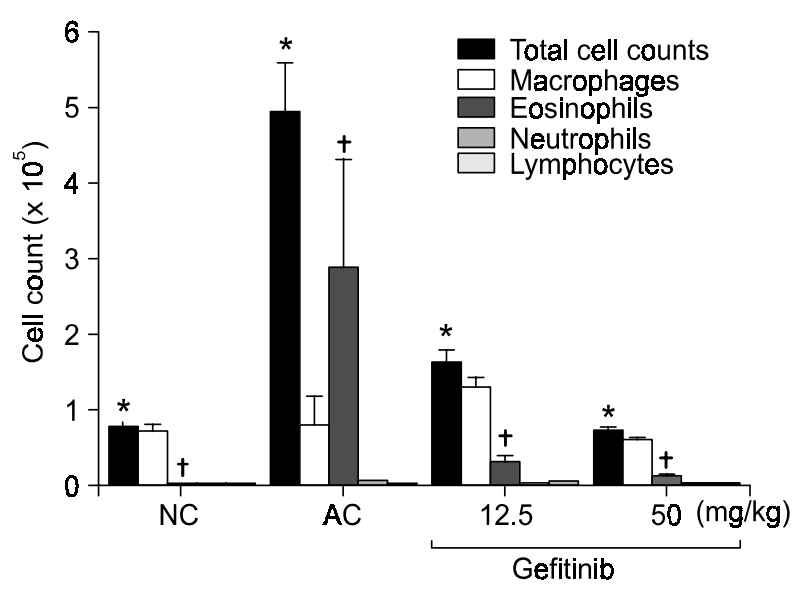

Figure 1. Gefitinib inhibits the recruitment of eosinophils in the BAL fluid. After OVA challenge and gefitinib pretreatment $(12.5 \mathrm{mg} / \mathrm{kg}$ and $50 \mathrm{mg} / \mathrm{kg}$ ), BALF were collected at $72 \mathrm{~h}$ after the last intranasal OVA challenge, and which were used for total BAL cell count and differential cell counts. ${ }^{*} P=0.001,{ }^{\dagger} P=0.002$. Values are reported as mean \pm SEM. NC, normal control; AC, asthma control. 
A

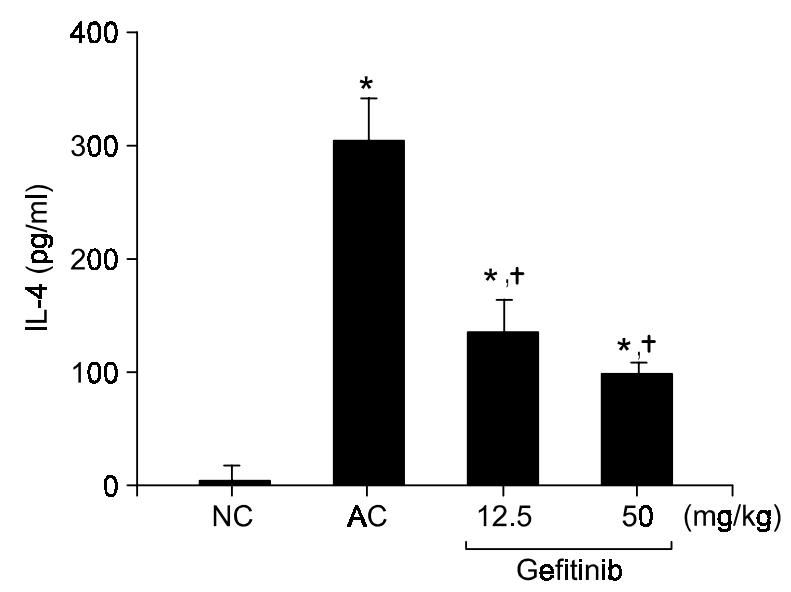

B

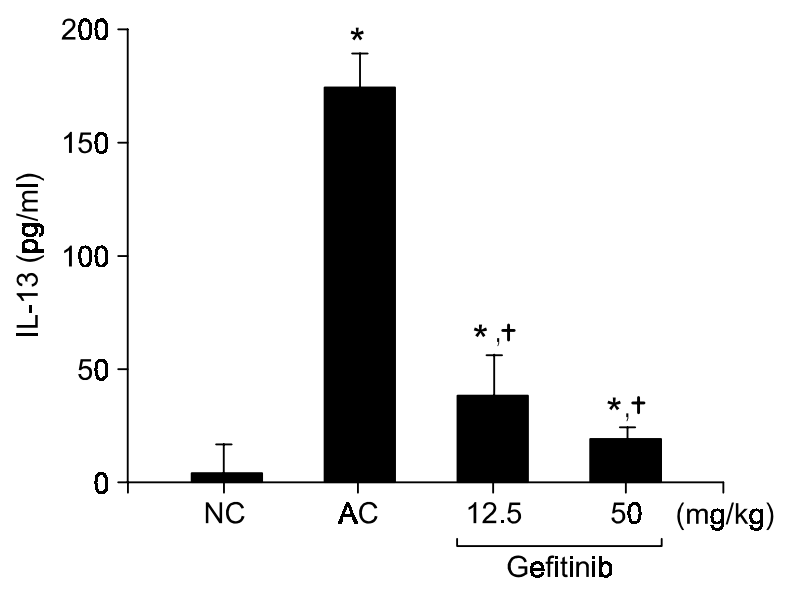

Figure 2. IL-4 (A) and IL-13 (B) levels in BALF supernatant of each group. After OVA challenge and gefitinib pretreatment $(12.5 \mathrm{mg} / \mathrm{kg}$ and 50 $\mathrm{mg} / \mathrm{kg}$ ), BALF were collected at $72 \mathrm{~h}$ after the last intranasal OVA challenge, and their supernatants were collected after centrifuge for ELISA of IL-4 and IL-13. ${ }^{*} P<0.05$ compared with NC, ${ }^{\dagger} P<0.05$ compared with AC. Values are reported as mean $\pm \mathrm{SEM}$. NC, normal control; AC, asthma control.
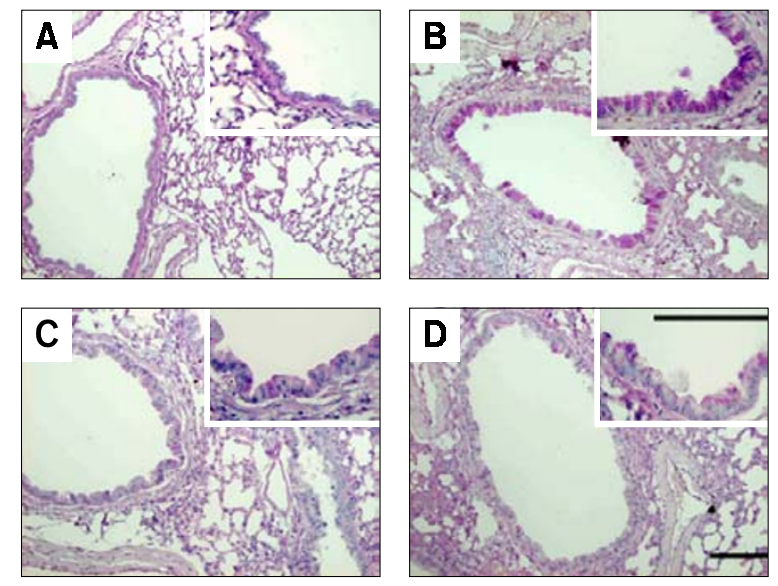

Figure 3. Photomicrographs of the effect of gefitinib on AB/PAS staining in bronchial epithelium in mice sensitized to OVA. (A) Control mice, (B) OVA-sensitized, and -challenged mice, (C) OVA-mice pretreated with gefitinib $(12.5 \mathrm{mg} / \mathrm{kg})$, and (D) OVA-mice pretreated with gefitinib $(50 \mathrm{mg} / \mathrm{kg}$ ) for 5 days were sacrificed, and their lung tissues were prepared for AB/PAS staining. Photomicrographs were shown at $\times 200$ magnification; inserts show magnification at $\times 400$ (bars $=100 \mu \mathrm{m})$.

OVA increased the AB/PAS-stained area (40.03 \pm $7.65 \%$ of epithelium; $P<0.05$ ). Pretreatment with gefitinib inhibited goblet cell metaplasia in a dosedependent manner $[21.91 \pm 4.69 \%$ of epithelium in mice pretreated with $12.5 \mathrm{mg} / \mathrm{kg}$ gefitinib; $15.18 \pm$ $4.17 \%$ of epithelium in mice pretreated with $50 \mathrm{mg} / \mathrm{kg}$ gefitinib; $P<0.05$ compared with Asthma control group (AC)]; Figures 3 and 4 . These results indicate that gefitinib decreases OVA-induced goblet cell

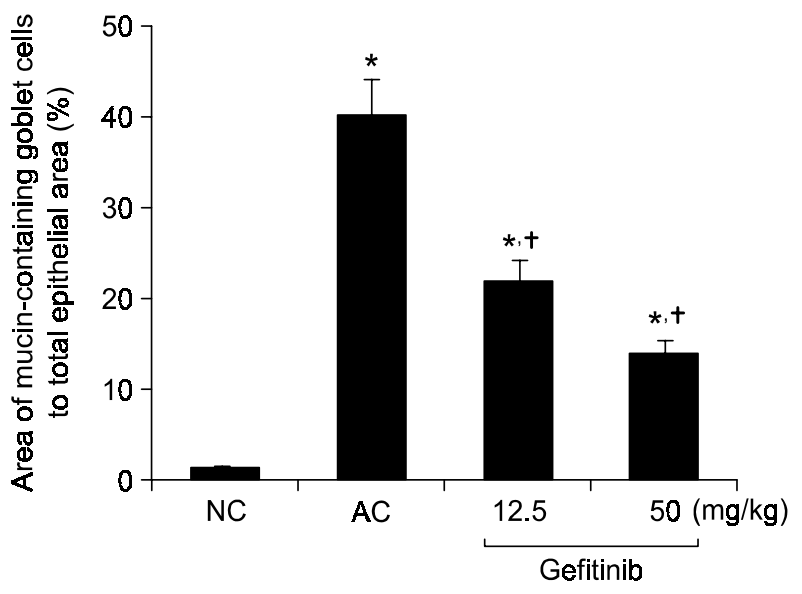

Figure 4. Gefitinib decreases the percentage of bronchial epithelium area stained with $A B / P A S$. After AB/PAS staining, the images of each group were captured and positively stained airway epithelial areas were calculated by the SigmaScan Pro Program at $\times 400$ magnification. ${ }^{*} P<0.05$ compared with $\mathrm{NC},{ }^{\dagger} P<0.05$ compared with AC, $n=5$ per group. Values are expressed as means \pm SEM. $\mathrm{NC}$, normal control; AC, asthma control.

metaplasia in the airway epithelium of mice.

\section{Immunohistochemical expression of P-EGFR}

There was strong P-EGFR staining in the epithelial cells of OVA-induced allergic airways. In contrast, pretreatment with gefitinib reduced the P-EGFR immunoreactivity in a dose-dependent manner. The level of P-EGFR immunoreactivity decreased in proportion to the AB/PAS-stained area in each group (Figure 5). 

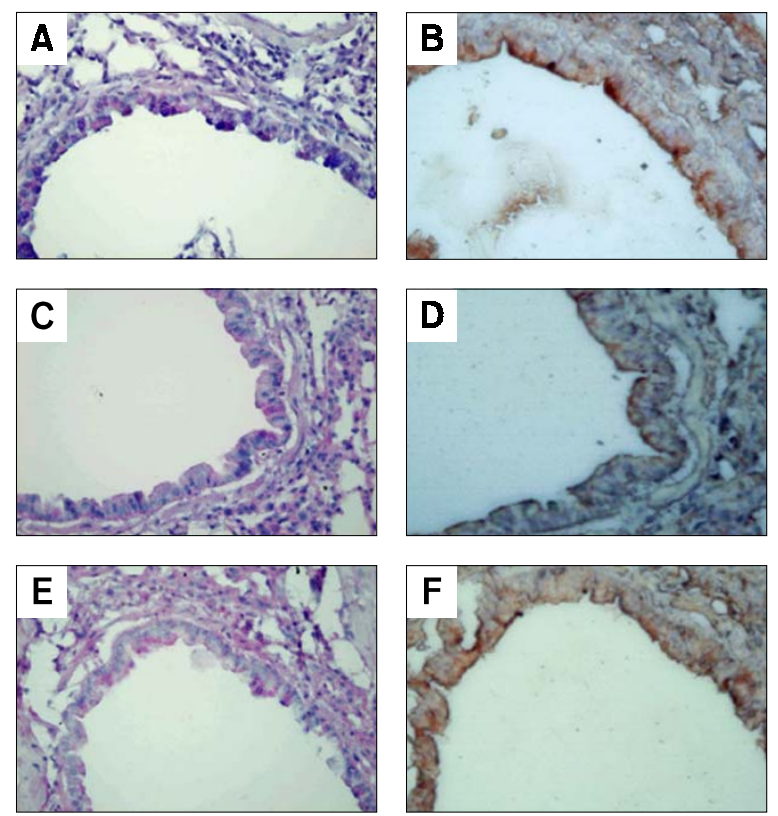

G

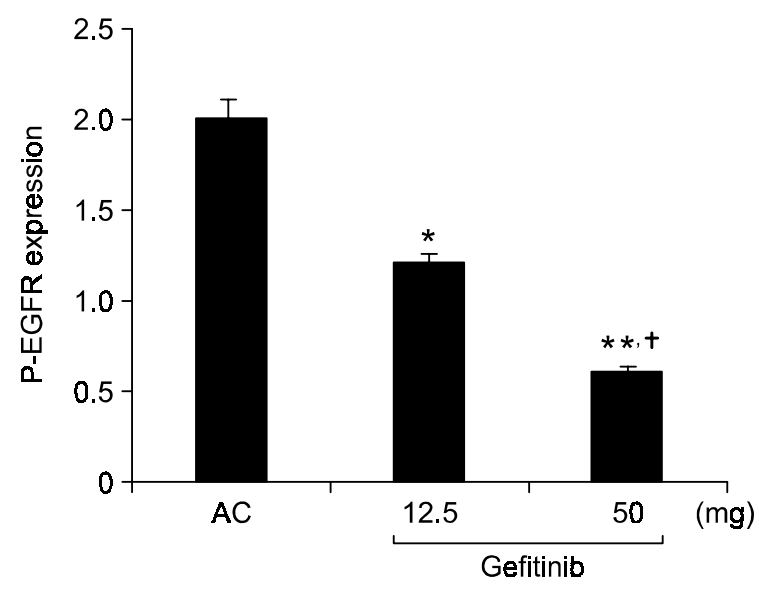

Figure 5. The comparison of expression of AB/PAS and P-EGFR immunohistochemical staining in mice airways. Tissues of OVA-sensitized, and -challenged mice were stained with (A) AB/PAS, and (B) an antibody specific for P-EGFR. Tissues of gefitinib (12.5 mg/kg) pretreated mice were stained with (C) AB/PAS, and (D) a P-EGFR specific antibody. Tissues of higher dose gefitinib (50 mg/kg) group were stained with (E) AB/PAS, and (F) a P-EGFR specific antibody. (G) P-EGFR expression was determined by calculating the P-EGFR stained area per microscopic field for each group. All images were shown and calculated at $\times 400$ magnification. ${ }^{*} P<0.05$; ${ }^{* *} P<0.01$ compared with control, ${ }^{\dagger} P<0.05$ compared with $12.5 \mathrm{mg} / \mathrm{kg}$ group, $n=5$ per group.

\section{Immunoblotting for activated EGFR}

The immunoblot analysis of lung tissue identified the presence of activated-EGFR protein in each group. We performed Western blot analysis to detect PEGFR, P-Akt and P-44/42 MAPK, because Akt and MAPK are downstream in the EGFR cascade. In OVA-sensitized mice, exposure to OVA increased the expression of P-EGFR, P-Akt and P-44/42 MAPK, and treatment with gefitinib inhibited the expression of them (Figure 6).

\section{Effect of gefitinib on AHR}

Mice sensitized to OVA and challenged with intranasal administration of OVA developed increases in airway responsiveness to methacholine compared with normal control mice $(P<0.02)$. Intragastric administration of gefitinib reduced airway responsiveness to methacholine in mice challenged with OVA compared with the responsiveness of untreated mice challenged with OVA $(P<0.02$, Figure 7$)$.

\section{Discussion}

In this study, we have investigated whether the EGFR tyrosine kinase inhibitor, gefitinib can reduce allergic inflammation in the airway epithelial cells of mice. Our

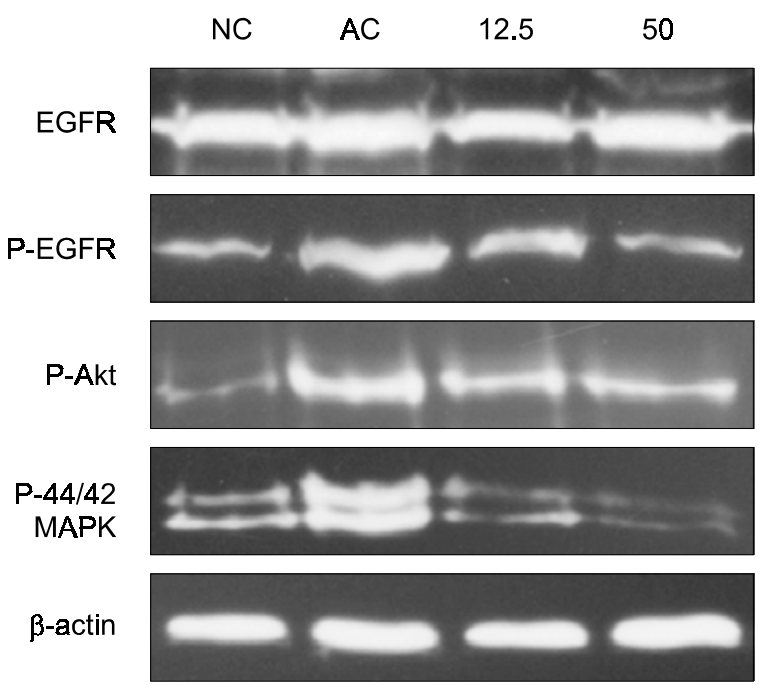

Figure 6. Effects of gefitinib on P-EGFR, P-Akt and P-44/42 MAPK expression in OVA-induced asthma model. Lung tissues of each group were lysed with whole lysis buffer, and a protease inhibitor cocktail was added. P-EGFR, P-Akt, and P-44/42 MAPK were identified by Western blot analysis using anti-P-EGFR, anti-P-Akt, and anti-P-44/42 MAPK antibodies. NC, normal control; AC, asthma control.

results show that exposure to OVA induces the recruitment of eosinophils, the release of IL-4 and IL-13, and an increase in airway hyperresponsiveness in 


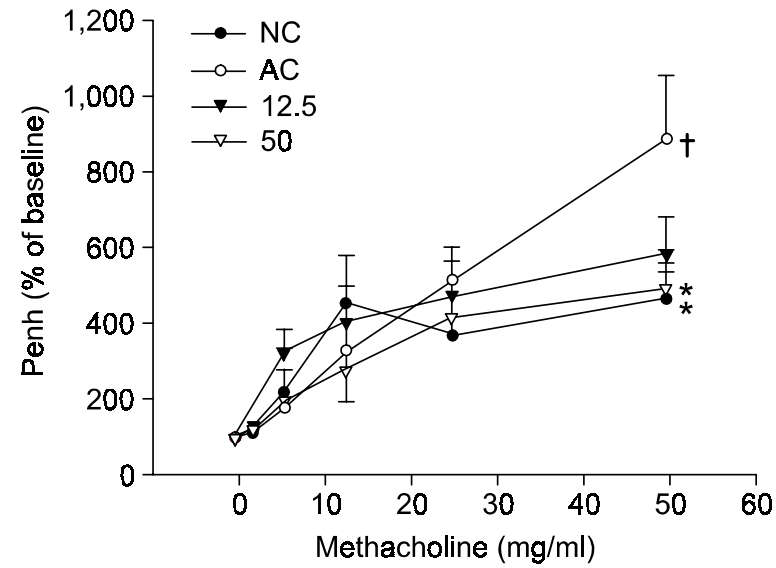

Figure 7. Gefitinib inhibited the developed AHR. Enhanced pauses (Penh) were measured at $24 \mathrm{~h}$ after the final OVA challenge using whole-body plethysmograph. Mice were exposed for 3 min subsequently to increasing concentrations of nebulized methacholine in PBS. The Penh values were expressed for each methacholine concentration $(3-50 \mathrm{mg} / \mathrm{ml})$ as a percentage of the baseline Penh value. ${ }^{*} P<$ 0.02 compared with $\mathrm{NC},{ }^{\dagger} P<0.02$ compared with $\mathrm{AC}, n=5$ per group Values are reported as mean \pm SEM. NC, normal control; AC, asthma control; 12.5 , gefitinib $12.5 \mathrm{mg} / \mathrm{kg} /$ day; 50 , gefitinib 50 $\mathrm{mg} / \mathrm{kg} / \mathrm{day}$.

mice. Pretreatment with gefitinib inhibits the activation of EGFR and Akt, reduces the release of Th2 cytokines from airway epithelium, and decreases the recruitment of eosinophils into airway epithelium. In fact, EGFR expression is increased in bronchial epithelium in adult and childhood asthma and there is an increasing number of studies using EGFR to regulate airway inflammation in asthma (Amishima et al., 1998; Polosa et al., 2002; Fedorov et al., 2005). However, it is not well known the mechanisms that EGFR tyrosine kinase inhibitor inhibits allergic airway inflammation.

Protein tyrosine kinase signaling cascades have been shown to be important in the activation and proliferation of inflammatory cells and resident airway cells. For example, EGFR plays an essential role in airway inflammation, reflecting epithelial damage and activation, and its expression increases in proportion to the severity of the asthma (Amishima et al., 1998; Puddicombe et al., 2000; Burgel and Nadel, 2004; Wong, 2005). EGFR is a $170-\mathrm{kDa}$ membrane glycoprotein which is activated by multiple ligands including EGF, TGF- $\alpha$, heparin binding (HB)-EGF, amphiregulin, $\beta$-cellulin, and epiregulin. These protein ligands are synthesized as transmembrane precursors and are cleaved by metalloproteases (TNF-alpha converting enzyme, TACE) to release the mature soluble growth factor. In asthma model, Th2 cytokines released from Th2 cells, especially IL-4 and IL-13, may activate the TACE on bronchial epithelial cells,

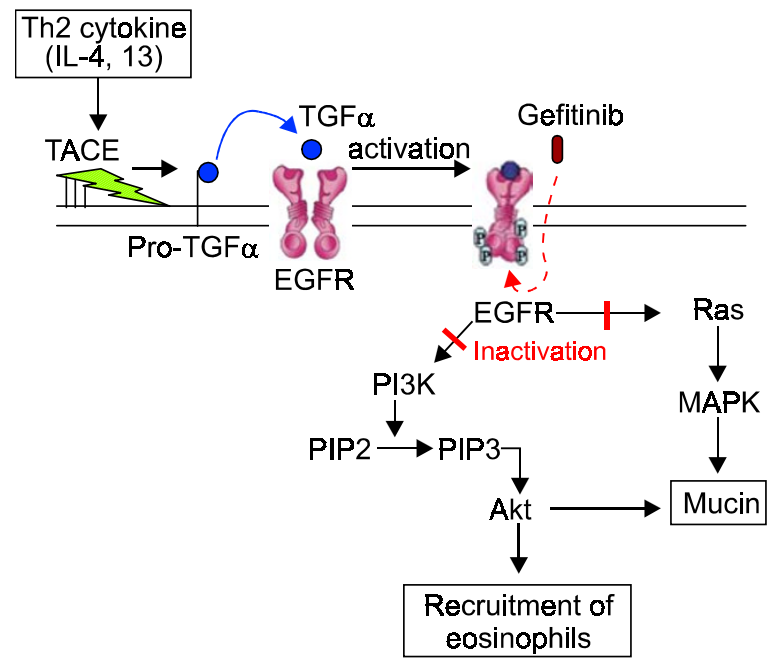

Figure 8. Model for the inhibition of mucin and eosinophils by gefitinib. This model combines others' previous results on mechanisms responsible for the ability of Th2 cytokines to activate TNF- $\alpha$-converting enzyme (TACE) and cleavage TGF $\alpha$ from pro-TGF $\alpha$ with the present results. In asthma model, Th2 cytokines released from Th2 cells, especially IL-13, may induce release of the soluble form of TGF $\alpha$ from the bronchial epithelium, which in turn can transactivate EGFR to induce mucin gene expression and recruitment of eosinophils. When gefitinib binds with EGFR, PI3K and Ras pathway were blocked. Therefore, mucin production and recruitment of eosinophils were inhibited by gefitinib.

resulting in cleavage of $T G F \alpha$, which in turn can transactivate EGFR tyrosine kinase signaling (Figure 8) (Lordan et al., 2002; King et al., 2004; Yoshisue and Hasegawa, 2004). Activation of tyrosine kinases invokes multiple down stream signaling pathway, including PI3K, MAPK and NF- $\mathrm{B}$, leading to cell differentiation, survival, proliferation, degranulation and chemotaxis (Burgel and Nadel, 2004).

In our study, we focused on the inhibitory effects of gefitinib in allergic airway inflammation. Gefitinib, an EGFR tyrosine kinase inhibitor, is a useful targeted therapeutic agent for non-small cell lung cancer (Gandara et al., 2004). EGFR bound its ligands, was dimerized and phosphorylated, which activates EGFR signaling cascade, leading to the induction of cell proliferation (Sako et al., 2000). Gefitinib blocks the signal transduction via EGFR by inhibiting its autophosphorylation and thus blocking downstream intracellular signaling. This results in the inhibition of cell proliferation and the reduced survival of cells (Ciardiello and Tortora, 2001). Recently, there have been reports that gefitinib could also reduce mucin production and suppress the MUC5AC gene in patients with bronchioloalveolar carcinoma who exhibit large amounts of mucus production (Kitazaki et al., $2005 a, b)$. Since tyrosine kinase signaling cascades are involved in almost all aspects of asthma patho- 
genesis, the possible therapeutic use of a tyrosine kinase inhibitor to treat asthma has been investigated in several studies (Duan et al., 2003, 2004; Vargaftig and Singer, 2003). Until now other studies have showed that EGFR tyrosine kinase inhibitors have anti-inflammatory effects in asthma model, but can not explain adequate mechanisms. In the current study, we tried to reveal mechanisms that is related with inhibitory effect of geftinib on allergic airway inflammation which included mucin production, eosinophilic infiltration and airway hyperresponsiveness. In other word, mucin production is related with EGFR phosphorylation and eosinophilic allergic inflammation is related with $\mathrm{PI} 3 \mathrm{~K} /$ Akt which is EGFR subsignal enzyme. To reveal these relationships we chose gefitinib which inhibits EGFR phosphorylation, PI3K/ Akt and MAPK, simultaneously. Based on previous studies (Chue et al., 2004; Lee et al., 2006a), selective Akt/PI3K or MAPK inhibitors reduce airway inflammation. In that study, they showed that airway inflammation or hyperresponsiveness are related with selective inhibitors. However, airway inflammation or mucin productions are not only related with only one pathway, we chose the gefitinib that inhibits both pathways. And the gefitinib doses chosen for the in vivo study were based on the literatures. The high dose gefitinib (50 mg/kg body weight per day) was based on previously reported work that yielded minimal gefitinib's toxic dose $(50 \mathrm{mg} / \mathrm{kg}$ ) (Sirotnak et al., 2000). The doses of gefitinib used in their study were all below the dose that would cause lethal toxicity on the schedule of administration used. And in our preliminary study, we confirmed that gefitinib's bone marrow suppression was not developed at high dose gefitinib group (data not shown). Thus, we chose a high dose of $50 \mathrm{mg} / \mathrm{kg}$ to minimize toxicity for the present study.

Recently, the activation of EGFR was shown to induce goblet cell proliferation and to increase MUC5AC gene expression and protein synthesis of MUC5AC in asthmatic patients (Takeyama et al., 2001). Amishima et al. (1998) also reported increased expression of EGF and EGFR in asthmatic human airway epithelium compared with their levels in a control population, suggesting that EGF may contribute to the pathophysiology of bronchial asthma. EGF and eosinophilderived TGF- $\alpha$, another natural ligand for the EGFR, have been shown to stimulate MUC5AC mucin gene expression and protein synthesis in a human airway epithelial cell line, and goblet cell metaplasia (Burgel and Nadel, 2004). The expression and activation of EGFR causes goblet cell metaplasia from Clara cells by a process of cell differentiation (Nadel and Takeyama, 1999; Nadel, 2001; Nadel and Burgel, 2001; Lee et al., 2006b). These goblet cell metaplasia and increased mucin production are important factors contributing to disease pathogenesis. We examined the effects of gefitinib on goblet cell metaplasia. Our results show that gefitinib significantly and dosedependently reduces goblet cell metaplasia, but does not totally inhibit it. For this result, the regulation of mucin expression (goblet cell metaplasia) is influenced by elaborate cross-link between signaling cascades instigated by products of the environment, immune cells, and epithelial cells themselves (Andrianifahanana et al., 2006). Because mucin production is not exclusively influenced by EGFR, OVA-induced goblet cell metaplasia is not totally inhibited by gefitinib.

Eosinophils are effector cells that play an important role in the pathophysiology of allergic disease. Eosinophil recruitment to sites of allergic inflammation depends on the concerted action of a variety of molecules, including chemokines, and activation of PI3K (Sotsios and Ward, 2000). IL-4 and IL-13 are chemotactic for eosinophils, which are principal elements in the pathogenesis of allergic inflammation (Rankin et al., 1996; Humbert et al., 1997). Eosinophil transmigration into the airways is a complex process that is coordinated by Th2 cytokines and several adhesion molecules (Lukacs, 2001). IL-4 regulates allergic inflammation and development of eosinophils by promoting Th2 cell differentiation, and mucus hypersecretion (Moser et al., 1992; Takeyama et al., 1999). IL-13 promotes B cell differentiation and is capable of inducing isotype-switching in B cells to produce $\lg E$ (Cocks et al., 1993). Recent studies suggest that PI3K plays a pivotal role in the recruitment and activation of eosinophils by induction of the Th2 response (Palframan et al., 1998; Myou et al., 2003; Lee et al., 2006a). PI3K is a signal transduction enzyme, which phosphorylates the D3 position of the inositol ring of phosphoinositide and its phosphorylated derivatives (Vanhaesebroeck and Waterfield, 1999). This phosphorylation then stimulates the catalytic activity of Akt, resulting in the subsequent phosphorylation of a host of other proteins which affect cell growth, cell cycle entry, and cell survival (Datta et al., 1997). Gefitinib is associated with the inhibition of EGFR and with two main downstream signaling pathways, those involving MAPK and PI3K/Akt. In recent years, a second pathway, downstream of PI3K/Akt, has become a focus of interest, and is currently receiving much attention as a primary regulator of mammalian cell proliferation and migration (Cantley, 2002; Pinho et al., 2005). Our results show that gefitinib reduces the level of Th2 cytokines (IL-4 and IL-13), the expression of P-Akt and the eosinophil count in BALF. These findings are in agreement with a recent report that tyrosine kinase signaling cascades are involved in almost all of the pathogenic processes of asthma (Vargaftig and Singer, 2003; Wong, 2005). 
With regard to AHR, the exact mechanism has not been clearly understood until now. It is believed that the eosinophils infiltrating the asthmatic lung degranulate to release tissue-damaging granular proteins, such as the major basic protein and eosinophil peroxidase, as well as release oxygen free radicals. These mediators, acting in concert, may then cause airway epithelial damage, resulting in the development of AHR (Laitinen et al., 1985; Pretolani et al., 1994). We measured AHR to methacholine by an invasive method using body plethysmography (Cho et al., 2004). Our results show that gefitinib significantly and dosedependently inhibits OVA-induced AHR to methacholine, possibly as a result of multiple mediators.

Bronchial asthma is a complex inflammatory lung disease and is multifactorial in origin, a pathogenic process mediated by multiple inflammatory cells and mediators. Protein tyrosine kinase signaling cascades are essential for the activation and proliferation of inflammatory cells and airway resident cells; in particular, the EGFR signaling cascade is critical to the process of allergic inflammation. Our results demonstrate that the EGFR tyrosine kinase inhibitor gefitinib can effectively reduce allergic inflammation by decreasing OVA-induced Th2 cytokine production, eosinophil recruitment, mucin production, and AHR in a murine asthma model. These findings suggest that the inhibition of the EGFR cascade may have therapeutic potential in the treatment of asthma.

\section{Acknowledgement}

This work was supported by the Korea Research Foundation Grant (KRF-2004-041-E00145).

\section{References}

Amishima M, Munakata M, Nasuhara Y, Sato A, Takahashi T, Homma Y, Kawakami Y. Expression of epidermal growth factor and epidermal growth factor receptor immunoreactivity in the asthmatic human airway. Am J Respir Crit Care Med 1998;157:1907-12

Andrianifahanana M, Moniaux N, Batra SK. Regulation of mucin expression: Mechanistic aspects and implications for cancer and inflammatory diseases. Biochim Biophys Acta 2006;1765:189-222

Bogdan S, Klambt C. Epidermal growth factor receptor signaling. Curr Biol 2001;11:R292-5

Burgel PR, Nadel JA. Roles of epidermal growth factor receptor activation in epithelial cell repair and mucin production in airway epithelium. Thorax 2004;59:992-6

Cantley LC. The phosphoinositide 3-kinase pathway. Science 2002;296:1655-7

Cho JY, Miller M, Baek KJ, Han JW, Nayar J, Rodriguez M, Lee SY, Mcelwain K, Mcelwain S, Raz E, Broide DH.
Immunostimulatory DNA inhibits transforming growth factor-beta expression and airway remodeling. Am J Respir Cell Mol Biol 2004;30:651-61

Chue SC, Seow CJ, Duan W, Yeo KS, Koh AH, Wong WS. Inhibitor of p42/44 mitogen-activated protein kinase, but not p38 MAPK, attenuated antigen challenge of guinea pig airways in vitro. Int Immunopharmacol 2004;4:1089-98

Ciardiello F, Tortora G. A novel approach in the treatment of cancer: targeting the epidermal growth factor receptor. Clin Cancer Res 2001;7:2958-70

Cocks BG, De Waal Malefyt R, Galizzi JP, De Vries JE, Aversa G. IL-13 induces proliferation and differentiation of human B cells activated by the CD40 ligand. Int Immunol 1993; 5:57-63

Cohn L, Elias JA, Chupp GL. Asthma: mechanisms of disease persistence and progression. Annu Rev Immunol 2004; 22:789-815

Datta SR, Dudek H, Tao X, Masters S, Fu H, Gotoh Y, Greenberg ME. Akt phosphorylation of BAD couples survival signals to the cell-intrinsic death machinery. Cell 1997;91: 231-41

Deshmukh HS, Case LM, Wesselkamper SC, Borchers MT, Martin LD, Shertzer HG, Nadel JA, Leikauf GD. Metalloproteinases mediate mucin 5AC expression by epidermal growth factor receptor activation. Am J Respir Crit Care Med 2005; 171:305-14

Duan W, Kuo IC, Selvarajan S, Chua KY, Bay BH, Wong WS. Antiinflammatory effects of genistein, a tyrosine kinase inhibitor, on a guinea pig model of asthma. Am J Respir Crit Care Med 2003;167:185-92

Duan W, Chan JH, Wong CH, Leung BP, Wong WS. Anti-inflammatory effects of mitogen-activated protein kinase kinase inhibitor U0126 in an asthma mouse model. J Immunol 2004;172:7053-9

Fedorov IA, Wilson SJ, Davies DE, Holgate ST. Epithelial stress and structural remodelling in childhood asthma. Thorax 2005;60:389-94

Gandara DR, West H, Chansky K, Davies AM, Lau DH, Crowley J, Gumerlock PH, Hirsch FR, Franklin WA. Bronchioloalveolar carcinoma: a model for investigating the biology of epidermal growth factor receptor inhibition. Clin Cancer Res 2004;10:S4205-9

Humbert M, Durham SR, Kimmitt P, Powell N, Assoufi B, Pfister R, Menz G, Kay AB, Corrigan CJ. Elevated expression of messenger ribonucleic acid encoding IL-13 in the bronchial mucosa of atopic and nonatopic subjects with asthma. J Allergy Clin Immunol 1997;99:657-65

Kim EY, Lee EN, Lee J, Park HJ, Chang CY, Jung Da Y, Choi SY, Lee SK, Joh JW, Kim SJ. Two-signal blockade with anti-CD45RB and anti-CD154 monoclonal antibodies inhibits graft rejection via CD4-dependent mechanisms in allogeneic skin transplantation. Exp Mol Med 2006;38:284-94

King NE, Zimmermann N, Pope SM, Fulkerson PC, Nikolaidis NM, Mishra A, Witte DP, Rothenberg ME. Expression and regulation of a disintegrin and metalloproteinase (ADAM) 8 in experimental asthma. Am J Respir Cell Mol Biol 2004; 


\section{$31: 257-65$}

Kitazaki T, Fukuda M, Soda H, Kohno S. Novel effects of gefitinib on mucin production in bronchioloalveolar carcinoma; two case reports. Lung Cancer 2005a;49:125-8

Kitazaki T, Soda H, Doi S, Nakano H, Nakamura Y, Kohno S. Gefitinib inhibits MUC5AC synthesis in mucin-secreting non-small cell lung cancer cells. Lung Cancer 2005b;50: 19-24

Laitinen LA, Heino M, Laitinen A, Kava T, Haahtela T. Damage of the airway epithelium and bronchial reactivity in patients with asthma. Am Rev Respir Dis 1985;131:599-606

Lee KS, Lee HK, Hayflick JS, Lee YC, Puri KD. Inhibition of phosphoinositide 3-kinase delta attenuates allergic airway inflammation and hyperresponsiveness in murine asthma model. Faseb J 2006a;20:455-65

Lee SY, Kang EJ, Hur GY, Jung KH, Jung HC, Lee SY, Kim $\mathrm{JH}$, Shin $\mathrm{C}$, In KH, Kang KH, Yoo SH, Shim JJ. Peroxisome proliferator-activated receptor-gamma inhibits cigarette smoke solution-induced mucin production in human airway epithelial (NCl-H292) cells. Am J Physiol Lung Cell Mol Physiol 2006b;291:L84-90

Lordan JL, Bucchieri F, Richter A, Konstantinidis A, Holloway, JW, Thornber M, Puddicombe SM, Buchanan D, Wilson SJ, Djukanovic R, Holgate ST, Davies DE. Cooperative effects of Th2 cytokines and allergen on normal and asthmatic bronchial epithelial cells. J Immunol 2002;169:407-14

Lukacs NW. Role of chemokines in the pathogenesis of asthma. Nat Rev Immunol 2001;1:108-16

Moser R, Fehr J, Bruijnzeel PL. IL-4 controls the selective endothelium-driven transmigration of eosinophils from allergic individuals. J Immunol 1992;149:1432-8

Myou S, Leff AR, Myo S, Boetticher E, Tong J, Meliton AY, Liu J, Munoz NM, Zhu X. Blockade of inflammation and airway hyperresponsiveness in immune-sensitized mice by dominant-negative phosphoinositide 3-kinase-TAT. J Exp Med 2003;198:1573-82

Nadel JA, Takeyama K. Mechanisms of hypersecretion in acute asthma, proposed cause of death, and novel therapy. Pediatr Pulmonol Suppl 1999;18:54-5

Nadel JA. Role of epidermal growth factor receptor activation in regulating mucin synthesis. Respir Res 2001;2:85-9

Nadel JA, Burgel PR. The role of epidermal growth factor in mucus production. Curr Opin Pharmacol 2001;1:254-8

Ngoc PL, Gold DR, Tzianabos AO, Weiss ST, Celedon JC. Cytokines, allergy, and asthma. Curr Opin Allergy Clin Immunol 2005;5:161-6

Palframan RT, Collins PD, Severs NJ, Rothery S, Williams TJ, Rankin SM. Mechanisms of acute eosinophil mobilization from the bone marrow stimulated by interleukin 5 : the role of specific adhesion molecules and phosphatidylinositol 3-kinase. J Exp Med 1998;188:1621-32

Pinho V, Souza DG, Barsante MM, Hamer FP, De Freitas MS, Rossi AG, Teixeira MM. Phosphoinositide-3 kinases crit- ically regulate the recruitment and survival of eosinophils in vivo: importance for the resolution of allergic inflammation. J Leukoc Biol 2005;77:800-10

Polosa R, Puddicombe SM, Krishna MT, Tuck AB, Howarth $\mathrm{PH}$, Holgate ST, Davies DE. Expression of c-erbB receptors and ligands in the bronchial epithelium of asthmatic subjects. J Allergy Clin Immunol 2002;109:75-81

Pretolani M, Ruffie C, Joseph D, Campos MG, Church MK, Lefort J, Vargaftig BB. Role of eosinophil activation in the bronchial reactivity of allergic guinea pigs. Am J Respir Crit Care Med 1994;149:1167-74

Puddicombe SM, Polosa R, Richter A, Krishna MT, Howarth, $\mathrm{PH}$, Holgate ST, Davies DE. Involvement of the epidermal growth factor receptor in epithelial repair in asthma. Faseb J 2000;14:1362-74

Rankin JA, Picarella DE, Geba GP, Temann UA, Prasad B, Dicosmo B, Tarallo A, Stripp B, Whitsett J, Flavell RA. Phenotypic and physiologic characterization of transgenic mice expressing interleukin 4 in the lung: lymphocytic and eosinophilic inflammation without airway hyperreactivity. Proc Natl Acad Sci USA 1996;93:7821-5

Robinson DS, Hamid Q, Ying S, Tsicopoulos A, Barkans J, Bentley AM, Corrigan C, Durham SR, Kay AB. Predominant TH2-like bronchoalveolar T-lymphocyte population in atopic asthma. N Engl J Med 1992;326:298-304

Sako Y, Minoghchi S, Yanagida T. Single-molecule imaging of EGFR signalling on the surface of living cells. Nat Cell Biol 2000;2:168-72

Sirotnak FM, Zakowski MF, Miller VA, Scher HI, Kris MG. Efficacy of cytotoxic agents against human tumor xenografts is markedly enhanced by coadministration of ZD1839 (Iressa), an inhibitor of EGFR tyrosine kinase. Clin Cancer Res 2000;6:4885-92

Sotsios Y, Ward SG. Phosphoinositide 3-kinase: a key biochemical signal for cell migration in response to chemokines. Immunol Rev 2000;177:217-35

Takeyama K, Dabbagh K, Lee HM, Agusti C, Lausier JA, Ueki IF, Grattan KM, Nadel JA. Epidermal growth factor system regulates mucin production in airways. Proc Natl Acad Sci USA 1999;96:3081-6

Takeyama K, Fahy JV, Nadel JA. Relationship of epidermal growth factor receptors to goblet cell production in human bronchi. Am J Respir Crit Care Med 2001;163:511-6

Vanhaesebroeck B, Waterfield MD. Signaling by distinct classes of phosphoinositide 3-kinases. Exp Cell Res 1999; 253:239-54

Vargaftig, BB, Singer M. Leukotrienes mediate part of Ova-induced lung effects in mice via EGFR. Am J Physiol Lung Cell Mol Physiol 2003;285:L808-18

Wong WS. Inhibitors of the tyrosine kinase signaling cascade for asthma. Curr Opin Pharmacol 2005;5:264-71

Yoshisue H, Hasegawa K. Effect of MMP/ADAM inhibitors on goblet cell hyperplasia in cultured human bronchial epithelial cells. Biosci Biotechnol Biochem 2004;68:2024-31 